This paper is published in the open archive of Mid Sweden University

DIVA http://miun.diva-portal.org

with permission of the publisher

Citation for the peer-reviewed published paper:

Logenius L, Friman L, Agnemo R. The influence of temperature and moisture on the physical properties of cellulose in the presence of metal chlorides and glucuronic acid. Nordic Pulp \& Paper Research Journal. 2008;23(1):8186 .

URL to article at publishers site:

http://dx.doi.org/10.3183/NPPRJ-2008-23-01-p081-086 


\title{
The influence of temperature and moisture on the physical properties of cellulose in the presence of metal chlorides and glucuronic acid
}

\author{
Louise Logenius, Linda Friman and Roland Agnemo, Mid Sweden University, Sundsvall, Sweden
}

KEYWORDS: Cellulose, Glucuronic acid, Temperature, Metal ions, Glucuronic acid, Viscosity

SUMMARY: The influence of $\mathrm{Mg}^{2+}, \mathrm{Ca}^{2+}$, and $\mathrm{Fe}^{3+}$ ions and glucuronic acid on the viscosity, after dry or humid heat-induced ageing, of two different cellulosic materials, cotton linters and dissolving pulp has been examined. The quantity of added metal ions was similar to that found in pulp.

In the cotton linters sheets, especially in those containing $\mathrm{Mg}^{2+}$, increased 5-hydroxymethyl-furfural (HMF) and 2-furaldehyde (furfural) concentrations were accompanied by decreased viscosity under dry conditions at $180^{\circ} \mathrm{C}(\mathrm{pH} 5)$. This indicates that $\mathrm{Mg}^{2+}$ ions can promote the Lewis-acid-catalyzed degradation of cellulose.

For cotton linters and dissolving pulp sheets, adding $\mathrm{Ca}^{2+}$ and $\mathrm{Mg}^{2+}$ ions is detrimental when ageing at $180^{\circ} \mathrm{C}$ under dry conditions ( $\mathrm{pH} 5$ ). Adding glucuronic acid increases the viscosity of aged cotton linters sheets, especially when $\mathrm{Ca}^{2+}$ and $\mathrm{Mg}^{2+}$ ions are present. Due to formation of complexes between the $\mathrm{Ca}^{2+}$ and $\mathrm{Mg}^{2+}$ ions and glucuronic acid, these ions reduce pulp viscosity to a smaller degree.

\section{ADDRESSES OF THE AUTHORS: Louise Logenius (louise.logenius@miun.se), Linda Friman (linda.friman@ sodra.com), Roland Agnemo (Roland.Agnemo@domsjoe.com) Mid Sweden University, Fibre Science and Communication Network, (FSCN), Department of Natural Science, SE-851 70, Sundsvall, Sweden. \\ Corresponding author: Louise Logenius}

High temperature, metal ions, moisture, oxidative conditions, alkaline and acidic $\mathrm{pH}$ induces chemical changes in the pulp. Under alkaline conditions such cooking and bleaching in the chemical pulp process, most of the lignin and extractives are removed. Although cellulose and hemicelluloses are quite stable under these conditions, alkaline degradation under the cooking stage and oxidative bleaching conditions introduces carbonyl groups in the cellulose and hemicellulose that can react further causing a decreased viscosity of the pulp (Lindberg 1956; Hon, Shiraishi 2001). Presence of transition metals and presence of lignin and other substances affects the cellulose during oxygen-alkali bleaching (Ericsson et al. 1971). In the viscose process, the viscosity of the pulp is reduced through a series of complex reactions to finally be regenerated. Metal ions are used as catalysts for the viscosity reduction of the pulp (Koutu, Bhagwat 1998).

The acid hydrolysis of cellulose and hemicelluloses is a rapid reaction that increases with increasing acid strength and temperature. The acid hydrolysis of cellulose (1) initially yields glucose (2), which can form 5hydroxymethyl-furfural (HMF; 3) (Fig 1, A) (Hon, Shiraishi 2001).
The thermal degradation of cellulose (1) at low to moderate temperatures yields 5-hydroxy-2-methyl-furfural (HMF, 3), which can decompose to form 2-furaldehyde (furfural, 4) (Fig 1, B) (Emsley, Stevens 1994). Furfural may also be formed via levoglucosan (5) (Fig 1, C) (Fagerson 1969; Emsley, Stevens 1994; Li et al. 2005).

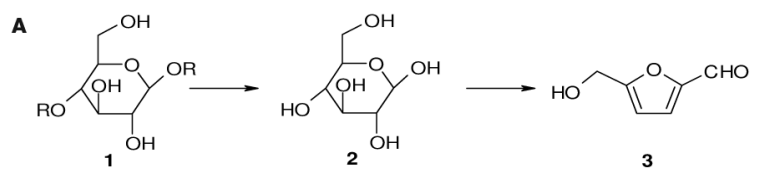

B
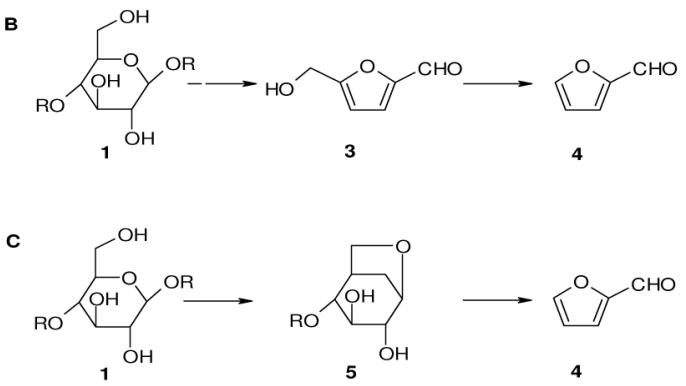

Fig 1. Different routes of cellulose (1) degradation.

A: Hydrolytic degradation: formation of 5-hydroxymethyl-furfural (HMF, 3) via glucose (2)

B: Thermal degradation: formation of HMF (3) and 2-furaldehyde (furfural, 4).

C: Thermal degradation: formation of levoglucosan (5) and furfural (4).

The rate of carbohydrate oxidation depends on $\mathrm{pH}$, moisture, temperature, access to oxidizing agents, and the presence of transition-metal ions (Williams et al. 1977; Shafizadeh, Bradbury 1979; Garves 1981; Bicchieri, Papa 1996; Kolar 1997; Strlic et al. 2000; Hon, Shiraishi 2001; Calvini, Gorassini 2002; Selih et al. 2007). High temperature, moisture, and access to oxygen all can reduce cellulose viscosity (Shafizadeh, Bradbury 1979; Emsley, Stevens 1994, Emsley et al. 2000a; Withmore, Bogaard 1994; Zou et al. 1996; Strlic et al. 2000). Oxidized glucose units in the cellulose chain are capable of further reactions, leading to the cleavage of the cellulose chain (Rapson, Corbi 1964; Luetzow, Theander 1974).

Water evolves via the thermal degradation of carbohydrates; therefore, a hydrolytic scission route prevails over oxidative degradation at low or moderate temperatures under dry conditions (Withmore, Bogaard 1994; Scheirs et al. 2001).

Metal ions occur naturally in wood. Some of the most abundant metal ions in wood are sodium (10-100 ppm), manganese (10-100 ppm), iron (10-100 ppm), barium (10-100 ppm), zinc (10-100 ppm), magnesium (100-400 ppm), potassium (400-1000 ppm), and calcium (400$1000 \mathrm{ppm}$ ) (Stenius 2000). During the pulping processes, 
metal ions can be added to the pulp; these ions derive from process equipment, process water, and process chemicals (Bouchard et al. 1995; Lapierre et al. 1997; Friman et al. 2003).

Transition-metal ions catalyze many chemical reactions in wood and pulp, and are therefore considered the most harmful metals in the pulping processes. Unlike transition metals, alkali, and alkaline earth metals are mostly considered beneficial or harmless to pulp and paper brightness (Czeipel 1960; Bicchieri, Papa 1996; Calvini, Gorassini 2002; Selih et al. 2007). Iron catalyzes the cleavage of the 1-4 glycosidic bond and copper the cleavage of the anhydroglucose ring, leading to decreased cellulose viscosity (Bicchieri, Papa 1996).

Lewis acids can also degrade cellulose; the metal ions form a complex with the glycosidic oxygen and the metal cation (Sarybaeva et al. 1991; Bicchieri, Papa 1996; Strlic et al. 2001).

In paper conservation, salts of alkaline earth metals are added to paper to prevent discoloration and degradation caused by ageing. The effects of such treatments can be evaluated using accelerated ageing tests at high temperatures. The studies are mainly performed under neutral to alkaline conditions. The results reported are, however, not unambiguous; some indicate that $\mathrm{Mg}^{2+}$ ions are less effective at stabilizing against paper discoloration and degradation than $\mathrm{Ca}^{2+}$ ions are, under both dry and humid ageing conditions (Williams et al. 1977; Lienardy, Van Damme 1990; Kolar, Novak 1996; Bansa 1998). Adding alkaline earth metals to cellulose treated at $180^{\circ} \mathrm{C}$ reduces its viscosity, magnesium ions causing the largest decrease (Strlic et al. 2001).

Magnesium salts are sometimes added to the pulp; magnesium sulfate is added to stabilizing hydrogen peroxide during bleaching, magnesium hydroxide is used instead of sodium hydroxide, and magnesium salts can be added to avoid scaling, (Colodette et al. 1989; He et al. 2004; Yu et al. 2004). It is therefore important to increase our knowledge how alkaline earth metals influences the viscosity of the pulp.

In this paper, we examine how adding $\mathrm{Mg}^{2+}, \mathrm{Ca}^{2+}$, or $\mathrm{Fe}^{3+}$ ions, or these ions in combination with glucuronic acid, to cellulose influences its viscosity after dry or humid heat ageing under slightly acidic conditions.

\section{Materials and Methods}

\section{Cellulose}

Cotton linters pulp containing $98 \%$ cellulose and $2 \%$ hemicellulose was used; the pulp was essentially free of lignin and extractives. The carbohydrate composition of the cotton linters pulp after an acid wash was almost exclusively glucose (i.e., $>99 \%$ ).

A dissolving pulp containing $95 \%$ cellulose and $5 \%$ hemicellulose was used; the pulp was essentially free of lignin and extractives. The initial viscosity of the cotton linters pulp was $1300 \mathrm{~mL} / \mathrm{g}$. The corresponding value for the dissolving pulp was $500 \mathrm{~mL} / \mathrm{g}$.

\section{Acid wash}

Cotton linters pulp and dissolving pulp were washed with hydrochloric acid ( $\mathrm{HCl}, \mathrm{p} . \mathrm{a}$.) at $\mathrm{pH} 1.5$ and $1 \%$ pulp consistency for $2 \mathrm{~h}$ at $18^{\circ} \mathrm{C}$ and thereafter five times with Milli-Q water at the same pulp consistency. In the final washing stage, the pulps were soaked in the Milli-Q water for $30 \mathrm{~min}$ before being dewatered. The $\mathrm{pH}$ of the final filtrate was neutral.

\section{Impregnation}

To compare the effects of $\mathrm{Ca}^{2+}$ and $\mathrm{Mg}^{2+}$ ions on the heatinduced degradation of the cellulose, the same molar amount of $\mathrm{Ca}^{2+}$ or $\mathrm{Mg}^{2+}$ ions $(0.025 \mathrm{~mole} / \mathrm{kg})$ was added to the cotton linters sheets and dissolving pulp sheets. Thus, $\sim 600 \mathrm{ppm} \mathrm{Mg}^{2+}$ ions or $\sim 1000 \mathrm{ppm} \mathrm{Ca}^{2+}$ ions was added to the sheets. In contrast, the molar amount of added $\mathrm{Fe}^{3+}$ ions was much lower $\left(3.6 \times 10^{-4} \mathrm{~mole} / \mathrm{kg}\right)$, corresponding to $\sim 20 \mathrm{ppm} \mathrm{Fe}^{3+}$ ions. The amount of added glucuronic acid was $\sim 1.20 \%(\mathrm{w} / \mathrm{w})$.

The cotton linters suspension was adjusted to the appropriate $\mathrm{pH}(3,5$, or 8$)$ with hydrochloric acid (p.a.) or sodium hydroxide (p.a.) and sheets with a grammage of approximately $30 \mathrm{~g} / \mathrm{m}^{2}$ were then produced in a laboratory sheet former.

After being dried at room temperature, the sheets were stored in a desiccator overnight before impregnation. The solutions used for impregnation were as follows: $\mathrm{CaCl}_{2}$ (0.013 M), $\mathrm{FeCl}_{3}\left(5.2 \times 10^{-5} \mathrm{M}\right)$, or $\mathrm{MgCl}_{2}(0.012 \mathrm{M})$; or glucuronic acid (GlcA, $0.025 \mathrm{M})$; or glucuronic acid $(0.025 \mathrm{M})$ with added $\mathrm{FeCl}_{3}\left(3.8 \times 10^{-5} \mathrm{M}\right), \mathrm{CaCl}_{2}(0.013$ $\mathrm{M})$, or $\mathrm{MgCl}_{2}(0.012 \mathrm{M})$.

The solutions were adjusted to the same appropriate initial $\mathrm{pH}$ levels using hydrochloric acid or sodium hydroxide. The sheets were placed on a clean polyethylene film; $3 \mathrm{~mL}$ of the impregnation solution was added to the sheets, which contained $\sim 0.285 \mathrm{~g}$ of cellulose material. After $15 \mathrm{~min}$, the excess solution was removed by absorbing with blotting paper. The sheets were attached to the polyethylene film with adhesive tape and left to dry for $3 \mathrm{~h}$, after which they were placed in a desiccator overnight. Square sheets were cut from the laboratory sheets and the grammage was determined.

\section{Analysis of metal contents of the sheets}

The cotton linters reference sheets and the impregnated cotton linters sheets were analyzed for metals using ICPOES according to the procedure described in Friman et al. (2003).

\section{Analysis of glucuronic acid content}

The glucuronic acid content was analyzed according to the procedure described in Taylor and Buchanan-Smith (1992), with some modification.

First, $0.1 \mathrm{~g}$ samples of cellulose containing known amounts of glucuronic acid were prepared and treated according to the method for obtaining a calibration curve. As well, a reference sample of untreated cellulose was simultaneously prepared. Then, $0.1 \mathrm{~g}$ of glucuronic acid-impregnated sheet was heated with $2 \mathrm{~mL}$ of water in a sealed silica glass tube for $2 \mathrm{~h}$, after which $0.5 \mathrm{~mL}$ of 
the water extract was removed for analysis. To the water extracts, $3 \mathrm{~mL}$ of sulfuric acid solution (80\%), containing $\mathrm{NaBO}_{2} \times 4 \mathrm{H}_{2} \mathrm{O}(0.80 \mathrm{~g} / \mathrm{L})$, was added, along with $100 \mu \mathrm{L}$ of carbazole in $95 \%$ ethanol. The tubes were carefully mixed and put in a water bath at $60^{\circ} \mathrm{C}$ for $2 \mathrm{~h}$. The solutions were analyzed using a Cary 100 Bio UV-Vis spectrophotometer (Varian, Palo Alto, CA, USA) at $530 \mathrm{~nm}$.

\section{pH measurements}

The $\mathrm{pH}$ was measured according to SCAN-P 14:65, except that a solution of $\mathrm{NaCl}(100 \mathrm{mM})$ was used instead of water.

\section{GC-MS analysis}

To analyze the degradation products of the aged cellulose samples, 100 or $200 \mathrm{mg}$ of the cellulose sample was put into a glass vial and heated to $60^{\circ} \mathrm{C}$ for $15 \mathrm{~min}$. A solid phase microextraction (SPME) headspace syringe was used to adsorb the volatile substances. The analyses were carried out on a gas chromatograph connected to a DSQ single quadrupole mass spectrometer (Thermo Fisher, Waltham, MA, USA). A Varian VF-5ms GC column (30 $\mathrm{m}, 0.25 \mathrm{~mm}$ I.D., $0.25 \mu \mathrm{m}$ film thickness) was used to separate the substances. The helium carrier gas flow rate was $1.0 \mathrm{ml} / \mathrm{min}$. The injector temperature was set at $230^{\circ} \mathrm{C}$ and the $\mathrm{GC}$ temperature program was as follows: $40^{\circ} \mathrm{C}(1 \mathrm{~min})-.20^{\circ} \mathrm{C} / \mathrm{min} .-240^{\circ} \mathrm{C}(5 \mathrm{~min}$. $)$.

Relevant peaks were identified by MS by using electron impact $(70 \mathrm{eV})$ as ionization mode. The molecular ions of 5-hydroxymethyl-furfural $(\mathrm{m} / \mathrm{z}=126)$ and 2furaldehyde $(\mathrm{m} / \mathrm{z}=96)$, which are two of several degradation products, were identified.

\section{Heat-induced ageing of samples}

Cotton linters reference sheets and impregnated cotton linters sheets (treated with $\mathrm{Ca}^{2+}, \mathrm{Mg}^{2+}$, or $\mathrm{Fe}^{3+}$ ions; or glucuronic acid; or glucuronic acid in combination with $\mathrm{Ca}^{2+}, \mathrm{Mg}^{2+}$, or $\mathrm{Fe}^{3+}$ ions) were aged in a laboratory oven (at 120,150 , or $180^{\circ} \mathrm{C}$ ) or in a chamber pressurized with steam at $180^{\circ} \mathrm{C}$ for 30 minutes. The sheets aged under humid conditions were placed in a desiccator to dry overnight before determining the sheet viscosity.

Reference dissolving pulp sheets and impregnated dissolving pulp sheets (treated with $\mathrm{Ca}^{2+}, \mathrm{Mg}^{2+}$, or $\mathrm{Fe}^{3+}$ ions; or glucuronic acid; or glucuronic acid in combination with $\mathrm{Ca}^{2+}, \mathrm{Mg}^{2+}$, or $\mathrm{Fe}^{3+}$ ions) were aged at 120,150 , and $180^{\circ} \mathrm{C}$ for $2.5 \mathrm{~h}$ under dry conditions.

\section{Viscosimetric measurements}

The intrinsic viscosity of unaged and aged sheets of cotton linters pulp and of dissolving pulp was analyzed according to the SCAN-CM 15:99 method.

\section{Results and Discussion}

The dissolving pulp sheets and cotton linters sheets were impregnated with the following: $\sim 20 \mathrm{ppm}$ of $\mathrm{Fe}^{3+}$ ions, $\sim 600 \mathrm{ppm}$ of $\mathrm{Mg}^{2+}$ ions, or $\sim 1000 \mathrm{ppm}$ of $\mathrm{Ca}^{2+}$ ions; or $\sim 1.20 \mathrm{w} / \mathrm{w} \%$ of glucuronic acid; or glucuronic acid in combination with the amounts of metal ions presented in
Table 1. Amounts of $\mathrm{Ca}^{2+}, \mathrm{Mg}^{2+}, \mathrm{Fe}^{3+}$ ions and glucuronic acid (GlcA) in the sheets.

\begin{tabular}{lcccc}
\hline Sample & $\begin{array}{c}\mathrm{GlcA} \\
(\%)\end{array}$ & $\begin{array}{c}\mathrm{Fe}^{3+} \\
(\mathbf{p p m})\end{array}$ & $\begin{array}{c}\mathrm{Ca}^{2+} \\
(\mathbf{p p m})\end{array}$ & $\begin{array}{c}\mathrm{Mg}^{2+} \\
(\mathbf{p p m})\end{array}$ \\
\hline Reference & & $4 \pm 0.6$ & $12 \pm 3.3$ & $1 \pm 0.3$ \\
$\mathrm{CaCl}_{2}$ & & $8 \pm 1.5$ & $905 \pm 30$ & $3 \pm 1.3$ \\
$\mathrm{FeCl}_{3}$ & & $20 \pm 1.8$ & $22 \pm 3.5$ & $4 \pm 0.6$ \\
$\mathrm{MgCl}_{2}$ & & $8 \pm 1.9$ & $20 \pm 5.9$ & $600 \pm 24$ \\
$\mathrm{GlcA}$ & $1.24 \pm 0.04$ & $6 \pm 1.0$ & $12 \pm 7.5$ & $4 \pm 3$ \\
$\mathrm{GlcACaCl}_{2}$ & $1.19 \pm 0.04$ & $8 \pm 1.0$ & $995 \pm 50$ & $63 \pm 2$ \\
$\mathrm{GlcAFeCl}_{3}$ & $1.18 \pm 0.04$ & $24 \pm 1.0$ & $24 \pm 1.0$ & $4 \pm 1$ \\
$\mathrm{GlcAMgCl}_{2}$ & $1.24 \pm 0.04$ & $9 \pm 1.0$ & $20 \pm 11$ & $600 \pm 50$ \\
\hline
\end{tabular}

Table 1. The initial viscosity of the cotton linters was $1300 \mathrm{~mL} / \mathrm{g}$ and of the dissolving pulp $500 \mathrm{~mL} / \mathrm{g}$.

\section{Cotton linters pulp-influence of moisture and glucuronic acid on viscosity}

To investigate the change of viscosity during heatinduced ageing under dry and humid conditions, cotton linters sheets ( $\mathrm{pH} 5)$ were aged for 30 minutes; the sheets were impregnated with the following: $\mathrm{Ca}^{2+}, \mathrm{Mg}^{2+}$, or $\mathrm{Fe}^{3+}$ ions; or glucuronic acid; or glucuronic acid in combination with $\mathrm{Ca}^{2+}, \mathrm{Mg}^{2+}$, or $\mathrm{Fe}^{3+}$ ions. The sheet viscosity was measured on unaged and aged sheets.

After ageing for 30 minutes at $180^{\circ} \mathrm{C}$ under dry conditions, the decrease in viscosity was most pronounced in the samples impregnated with $\mathrm{Ca}^{2+}$ and $\mathrm{Mg}^{2+}$ ions (Fig 2a). $\mathrm{Fe}^{3+}$ ions seemed to have little effect on the viscosity of cellulose during dry ageing. Under humid conditions, the detrimental impact of $\mathrm{Ca}^{2+}$ and $\mathrm{Mg}^{2+}$ ions was significantly smaller. $\mathrm{Ca}^{2+}$ and $\mathrm{Mg}^{2+}$ ions are normally considered beneficial or at least not detrimental to pulp viscosity under alkaline conditions, but under dry and slightly acidic conditions they are obviously detrimental.

Adding glucuronic acid to the sheets decreases the cellulose degradation under dry conditions, especially in sheets containing $\mathrm{Ca}^{2+}$ and $\mathrm{Mg}^{2+}$ ions (Fig 2b). Under humid conditions, the sheets impregnated with glucuronic acid or glucuronic acid and $\mathrm{Fe}^{3+}$ ions have slightly higher viscosities than do the unimpregnated reference sheets and the sheets impregnated with only $\mathrm{Fe}^{3+}$ ions. Adding glucuronic acid seems to protect the cellulose from heat-induced degradation.

Tajmir-Riahi (1983) has suggested that a complex forms between $\mathrm{Ca}^{2+}$ ions and D-glucuronic acid. Figs $2 a$ and $b$ indicate that the glucuronic acid forms a complex with the metals, since the viscosity of the samples impregnated with glucuronic acid in combination with $\mathrm{Ca}^{2+}$ or $\mathrm{Mg}^{2+}$ ions aged under dry conditions drops significantly less than that of the samples containing only $\mathrm{Ca}^{2+}$ or $\mathrm{Mg}^{2+}$ ions. Complex formation probably occurs while preparing the impregnating solutions and may explain why $\mathrm{Ca}^{2+}$ or $\mathrm{Mg}^{2+}$ ions are less detrimental to cellulose viscosity when glucuronic acid is present.

\section{Cotton linters pulp-influence of pH on viscosity}

The influence of $\mathrm{pH}$ on the degradation of cotton linters was studied. Cotton linters sheets with initial $\mathrm{pH}$ levels of 3,5 , and 8 were aged at $180^{\circ} \mathrm{C}$ for 30 minutes under dry conditions; the viscosity levels were measured on unaged 


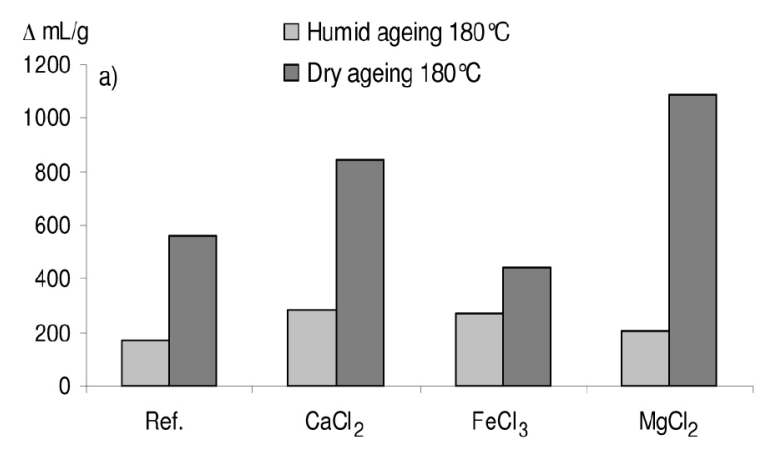

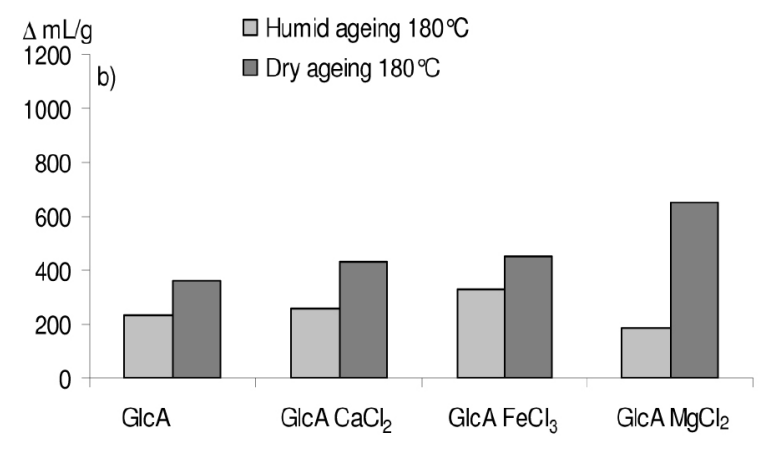

Figs $2 \mathrm{a}$ and $\mathrm{b}$. Decrease of viscosity $(\Delta \mathrm{mL} / \mathrm{g})$ of cotton linters reference sheets and impregnated sheets (treated with $\mathrm{Fe}^{3+}, \mathrm{Ca}^{2+}$, or $\mathrm{Mg}^{2+}$ ions; or glucuronic acid; or glucuronic acid in combination with $\mathrm{Fe}^{3+}, \mathrm{Ca}^{2+}$, or $\mathrm{Mg}^{2+}$ ions) (pH 5) aged for 30 minutes at $180^{\circ} \mathrm{C}$ under dry and humid conditions.

and aged sheets. A low $\mathrm{pH}$ increases the degradation of the cellulose (Fig 3), the decrease of viscosity most likely being caused by acid hydrolysis (Zou et al. 1994). Although the water content of the sheets is low during dry-oven ageing, sufficient water is produced during heat-induced ageing of cellulose (Scheirs et al. 2001).

If the sheets are impregnated with $\mathrm{Mg}^{2+}$ ions, the decrease in viscosity is even greater than that of the reference sheets at the same $\mathrm{pH}$ levels (Fig 3a). Adding glucuronic acid increased the viscosity at all $\mathrm{pH}$ levels (Figs 3 and $b$ ).

\section{Cotton linters pulp-formation of HMF and furfural}

The decrease in viscosity and the formation of 2-furaldehyde (furfural) are shown in Fig $4 a$. The viscosity of the samples containing $\mathrm{Ca}^{2+}$ and $\mathrm{Mg}^{2+}$ ions is significantly lower than that of the aged reference. The decrease in viscosity is correlated with the formation of 2-furaldehyde (furfural) (Emsley et al. 2000b; Soares et al 2001), which is formed from 5-hydroxymethyl-furfural (HMF, Fig 1, B) (Fagerson 1969; Emsley, Stevens 1994; Scheirs et al. 2001; Li et al. 2005).

Fig $4 b$ shows the decrease of viscosity and the formation of HMF; the amount of HMF is not correlated with the viscosity. The aged reference contains a large amount of HMF probably derived from the acid hydrolysis and thermal degradation of the cellulose. The sheets containing added $\mathrm{Mg}^{2+}$ ions also display a large amount of HMF, derived either from hydrolysis or from increased thermal degradation. As proposed in a previous work (Logenius et al. 2008), complexes form between the cation and the glucose unit, leading to a degradation reaction promoted by the metal cation acting as a Lewis acid. The formation of complexes between alkaline earth

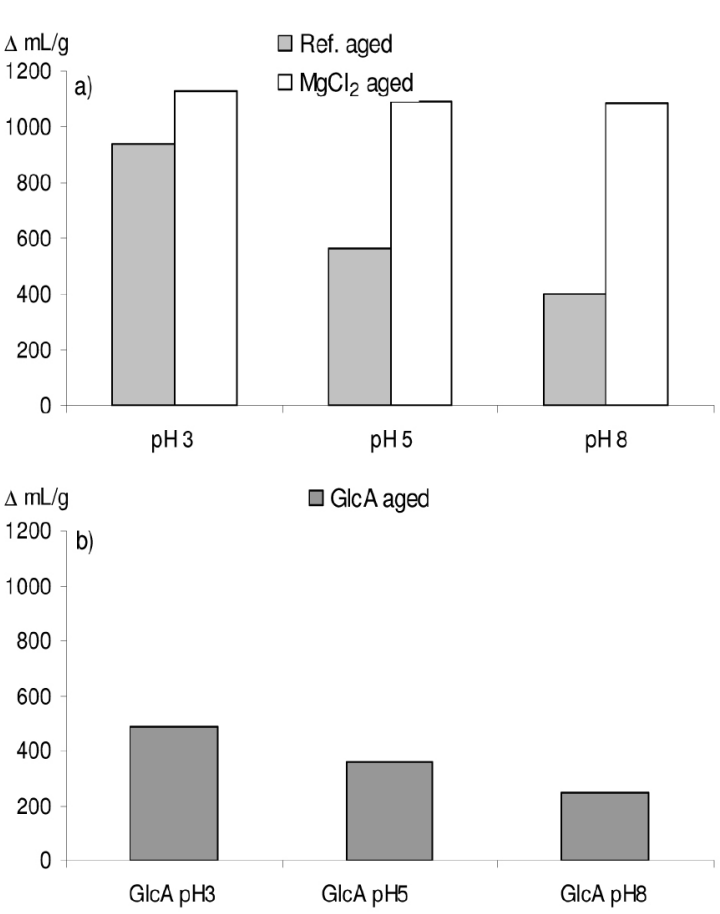

Figs 3a and 3b. Decrease of viscosity $(\Delta \mathrm{mL} / \mathrm{g})$ of cotton linters pulp sheets, cotton linters sheets impregnated with $\mathrm{Mg}^{2+}$ ions, and cotton linters sheets impregnated

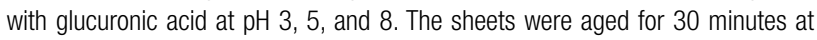
$180^{\circ} \mathrm{C}$ under dry conditions.

metal ions and the glucose unit was earlier proposed by Strlic et al. (2001) and Tajmir-Riahi (1988). Lewis-acidpromoted cleavage of the cellulose chain has been proposed by Sarybaeva et al. (1991).

Fig $4 c$ shows the correlation between decreased viscosity and the formation of HMF + furfural. $\mathrm{Mg}^{2+}$ and $\mathrm{Ca}^{2+}$ ions act as Lewis catalysts for the degradation of the cellulose.

\section{Dissolving pulp}

Fig $5 a$ shows the dissolving pulp reference sheets and sheets impregnated with $\mathrm{Ca}^{2+}, \mathrm{Mg}^{2+}$, or $\mathrm{Fe}^{3+}$ ions aged for 120,150 , or $180^{\circ} \mathrm{C}$ under dry conditions for $2.5 \mathrm{~h}(\mathrm{pH} \mathrm{5})$. At $120^{\circ} \mathrm{C}$, there is no decrease in viscosity compared to that of the reference sheets, except in sheets impregnated with $\mathrm{Mg}^{2+}$ ions; at 150 and $180^{\circ} \mathrm{C}$, however, viscosity also decreased in the sheets impregnated with $\mathrm{Ca}^{2+}$ ions. Alkaline earth metal ions reduce pulp viscosity under dry conditions at temperatures $>120^{\circ} \mathrm{C}$. Low levels $(20 \mathrm{ppm})$ of $\mathrm{Fe}^{3+}$ ions do not reduce pulp viscosity when ageing under dry conditions at slightly acidic $\mathrm{pH}(\mathrm{pH} 5)$.

When glucuronic acid is added to the sheets there is no significant change in viscosity at $120-180^{\circ} \mathrm{C}$ compared to that of the reference sheets (Fig 5b). The viscosity of the sheets impregnated with glucuronic acid and $\mathrm{Ca}^{2+}$ or $\mathrm{Mg}^{2+}$ ions added is higher than that of the sheets containing $\mathrm{Ca}^{2+}$ and $\mathrm{Mg}^{2+}$ ions.

When glucuronic acid is added to cotton linters sheets a slight increase in viscosity is obtained, for the dissolving pulp reference sheets there is a slight decrease. The difference between the behavior of cotton linters cellulose and dissolving cellulose can possibly be explained by the difference between the cellulose structure and composition of the materials (Philipp et al. 1969) and the ageing time. 

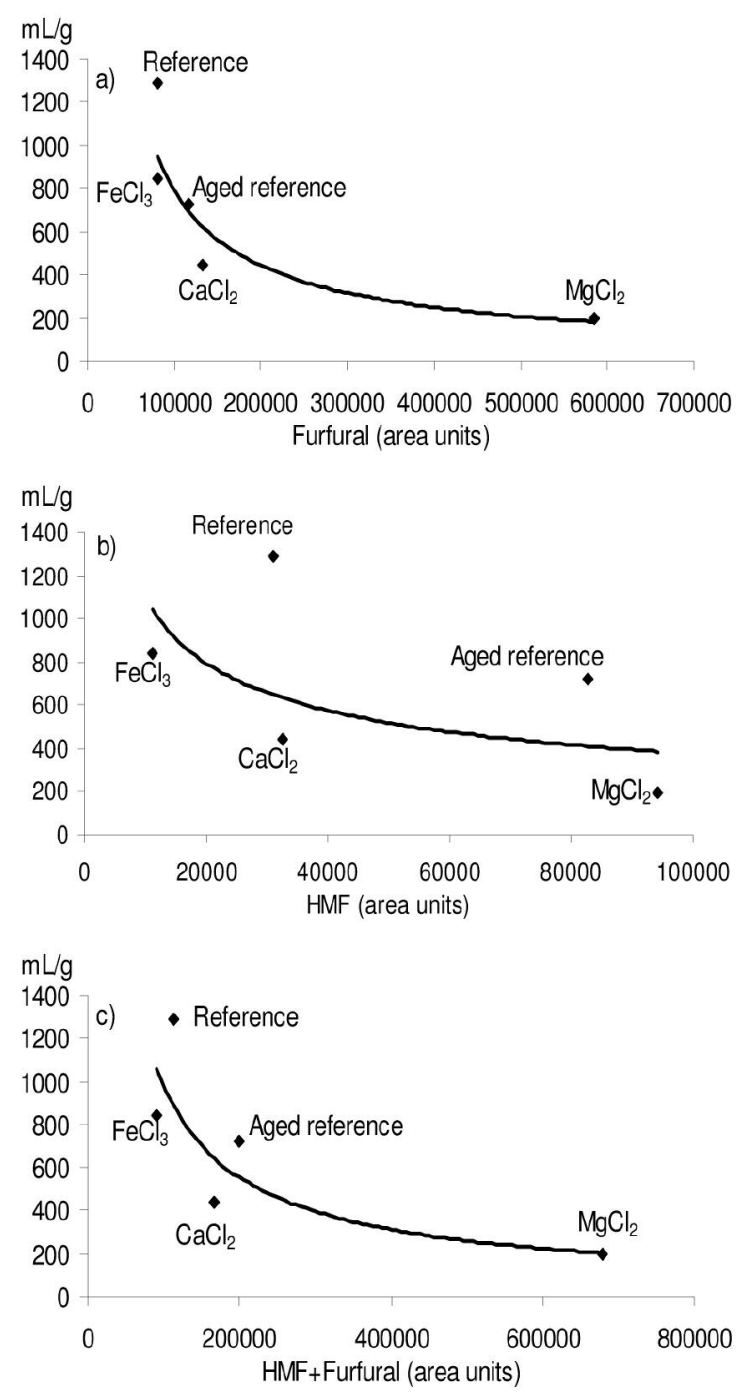

Figs $4 \mathrm{a}-\mathrm{c}$. Correlation between viscosity $(\mathrm{mL} / \mathrm{g})$ of reference sheets and sheets impregnated with $\mathrm{Ca}^{2+}, \mathrm{Mg}^{2+}$, or $\mathrm{Fe}^{3+}$ ions aged under dry conditions, at $180^{\circ} \mathrm{C}$ for 30 minutes, and formation of furfural, HMF, and HMF + furfural, respectively. HMF and furfural concentrations were analyzed using GC-MS analysis.

\section{Conclusions}

In the cotton linters sheets, especially those impregnated with $\mathrm{Mg}^{2+}$ ions, an increase in 5-hydroxymethyl-furfural (HMF) and 2-furaldehyde (furfural) concentration was accompanied by decreased viscosity. This indicates that $\mathrm{Mg}^{2+}$ ions can promote the Lewis-acid-catalyzed degradation of cellulose.

For cotton linters sheets and dissolving pulp sheets, adding $\mathrm{Ca}^{2+}$ and $\mathrm{Mg}^{2+}$ ions is detrimental to pulp viscosity when ageing at $180^{\circ} \mathrm{C}$ under dry conditions. Adding glucuronic acid increases the viscosity of the aged cotton linters sheets, especially when $\mathrm{Ca}^{2+}$ and $\mathrm{Mg}^{2+}$ ions are present.

\section{Acknowledgements}

Financial support from Mid Sweden University, FSCN, the Bo Rydin Foundation, the Knowledge Foundation, and EU Objective 1 is gratefully acknowledged. Thanks are also due to Domsjoe Fabriker AB and SCA Graphic Research AB for technical support. We thank Dr. Magnus Paulsson for his valuable comments.
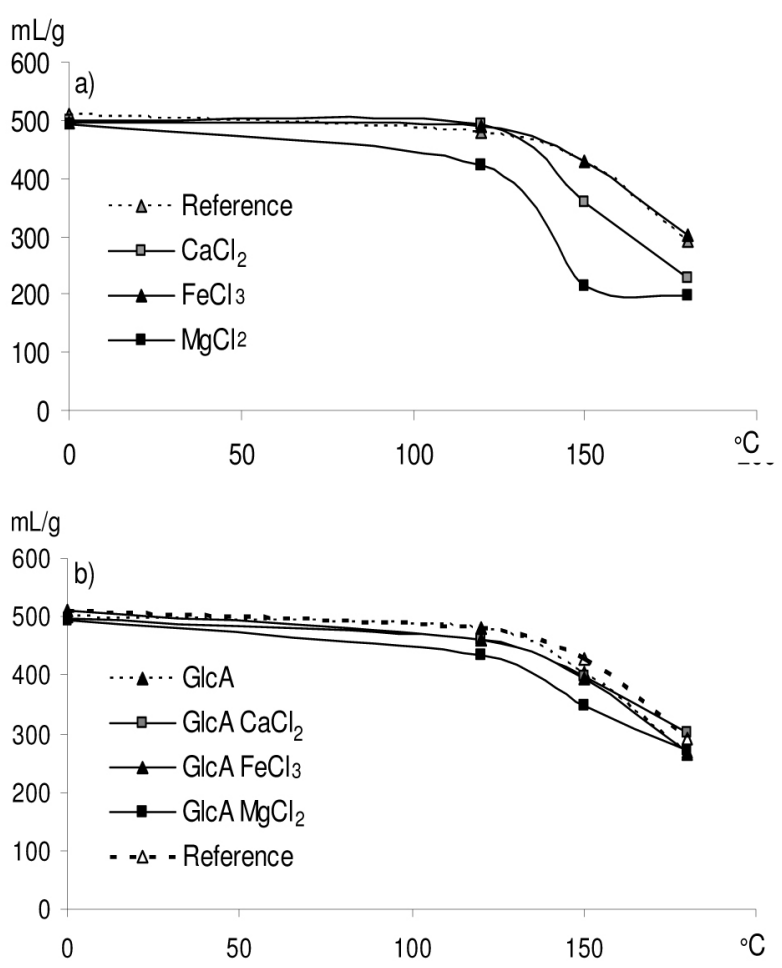

Figs $5 a$ and $b$. Viscosity $(\mathrm{mL} / \mathrm{g})$ of reference dissolving pulp sheets and impregnated dissolving pulp sheets (treated with $\mathrm{Ca}^{2+}, \mathrm{Mg}^{2+}$, or $\mathrm{Fe}^{3+}$ ions; or glucuronic acid; or glucuronic acid in combination with $\mathrm{Ca}^{2+}, \mathrm{Mg}^{2+}$, or Fe ${ }^{3+}$ ions) (pH 5), aged for $2.5 \mathrm{~h}$ at 120,150, or $180^{\circ} \mathrm{C}$ under dry conditions.

\section{Literature}

Bansa, H. (1998): Aqueous deacidification - with calcium or magnesium? Restaurator, 19(1), 1-40.

Bicchieri, M. and Papa, S. (1996): The degradation of cellulose with ferric and cupric ions in a low-acid medium, Restaurator, 17(3), 165-183.

Bouchard, J., Nugent, H.M. and Berry, R.M. (1995): A comparison between acid treatment and chelation prior to hydrogen peroxide bleaching of kraft pulp, J. Pulp Paper Sci. 21(6), J203-208.

Calvini, P. and Gorassini, A. (2002): The degrading action of iron and copper on paper. A FTIR-deconvolution analysis, Restaurator, 23(4), 205-221.

Colodette, J.L., Rothenberg, S. and Dence, C.W. (1989): Factors affecting hydrogen peroxide stability in the brightening of mechanical and chemimechanical pulps. Part III: Hydrogen peroxide stability in the presence of magnesium or combinations of stabilizers, J. Pulp Paper Sci. 15(2), J45-50.

Czeipel, T.P. (1960): The influence of selected metal traces on the color and color stability of purified cotton linters, Tappi, 43(4), 289-299.

Emsley, A.M. and Stevens, G.C. (1994): Kinetics and mechanisms of the low-temperature degradation of cellulose, Cellulose 1(1), 26-56.

Emsley, A.M., Xiao, X., Heywood, R.J. and Ali, M. (2000a): Degradation of cellulosic insulation in power transformers. Part 3: Effects of oxygen and water on ageing in oil, IEE. Proc. Sci. Meas. Technol. 147(3), 115-119.

Emsley, A.M., Xiao, X., Heywood, R.J. and Ali, M. (2000b): Degradation of cellulosic insulation in power transformers. Part 2: Formation of furan products in insulating oil, IEE Proc. Sci. Meas. Technol. 147(3) 110-114.

Ericsson, B., Lindgren, B.0. and Theander, 0. (1971): Factors influencing the carbohydrate degradation under oxygen-alkali bleaching, Svensk Papperstidning, 74(22), 757-765

Fagerson, I.S. (1969): Thermal degradation of carbohydrates: a review, J. Agr. Food Chem. 17(4), 747-750.

Friman, L., Logenius, L., Agnemo, R. and Högberg, H.-E. (2003): Comparison of metal profiles in thermomechanical pulping processes in which either hydrogen peroxide or dithionite bleaching is used, Paperi Puu, 85(6), 334-339.

Garves, K. (1981): Dehydration and oxidation of cellulose hydrolysis products in acidic solution, J. Wood Chem. Technol. 1(2), 223-235.

He, Z., Wekesa, M. and Ni, Y. (2004): Pulp properties and effluent characteristics 
from the $\mathrm{Mg}(\mathrm{OH}) 2$-based peroxide bleaching process, Tappi J. 3(12), 27-31. Hon D.N.-S. and Shiraishi, N. (2001): Wood and Cellulosic Chemistry, Marcel Dekker, New York, NY, USA, pp 443-445, 450-456, 470-478, 493-497, 891-893. Kolar, J. (1997): Mechanism of autoxidative degradation of cellulose, Restaurator, 18(4), 163-176.

Kolar, J. and Novak, G. (1996): Effect of various deacidification solutions on the stability of cellulose pulps, Restaurator, 17(1), 25-31.

Koutu, B.B. and Bhagwat, V.W. (1998): Effects of some metal ions on degradation of cellulose in alkaline media, IPPTA, 10(4), 77-82.

Lapierre, L., Paleologou, M., Berry, R.M. and Bouchard, J. (1997): The limits of metal removal from kraft pulp by acid treatment, J. Pulp Paper Sci. 23(11), J539-542.

Li, J., Henriksson, G. and Gellerstedt, G. (2005): Carbohydrate reactions during high-temperature steam treatment of aspen wood, Appl. Biochem. Biotechnol. 125(3), 175-188.

Lienardy, A. and Van Damme, P. (1990): Practical deacidification, Restaurator, 11(1), 1-21.

Lindberg, B. (1956): Alkaline hydrolysis of glycosidic linkages, Svensk Papperstidning, 15, 531-534.

Logenius, L., Friman, L. and Agnemo, R. (2008): The influence of temperature and moisture on the optical properties of cellulose in the precence of metal chlorides and glucuronic acid, Nord. Pulp Paper Res. J. 23(1), 72-80.

Luetzow, A.E. and Theander, 0. (1974): 6-Aldehydocelluloses - thermal instability, Beta-elimination and acid hydrolysis, Svensk Papperstidning, 77(9), 312-318.

Philipp, B., Baudisch, J. and Ruscher, CH. (1969): Influence of supramolecular structure on structural and chemical changes in the thermal degradation of cellulosic fibers, Tappi, 52(4), 693-698.

Rapson, W.H. and Corbi, J.-C. (1964): Colour reversion caused by degradation products of oxidized cellulose, Pulp Paper Mag. Can. 65, T459-T466.

Sarybaeva, R.I., Sultankulova, A.S., Vasilikova, T.V. and Afanasiev, V.A. (1991): Degradation of cellulose in the presence of Lewis acids, Cellul. Chem. Technol. 25(3-4), 199-210.

Scheirs, J., Camino, G. and Tumiatti, W. (2001): Overview of water evolution during the thermal degradation of cellulose, Eur. Polym. J. 37(5), 933-942.

Selih, V.S., Strlic, M., Kolar, J. and Philar, B. (2007): The role of transition metals in oxidative degradation of cellulose, Polym. Degrad. Stab. 92(8), 1476-1481.

Shafizadeh, F. and Bradbury, A.G.W. (1979): Thermal degradation of cellulose in air and nitrogen at low temperatures. J. Appl. Polym. Sci. 23(5), 1431-1442.

Soares, S., Ricardo, N.M.P.S., Heatley, F. and Rodrigues, E. (2001): Low tem- perature thermal degradation of cellulosic insulating paper in air and transformer oil, Polym. Int. 50(3), 303-308.

Stenius, P. (2000): Forest Products Chemistry, Fapet Oy, Helsinki, Finland, p. 54. Strlic, M., Kolar, J., Philar, B., Rychly, J. and Matisová-Rychlá, L. (2000): Chemiluminescence during thermal and thermo-oxidative degradation of cellulose, Eur. Polym. J. 36(11), 2351-2358.

Strlic, M., Kolar, J., Philar, B., Rychly J. and Matisová-Rychlá, L. (2001): Initial degradation processes of cellulose at elevated temperatures revisited: chemiluminescence evidence, Polym. Degrad. Stab. 72(1), 157-162.

Tajmir-Riahi, H.A. (1983): Sugar complexes with calcium ion: infrared spectra of crystalline D-glucuronic acid and its calcium complexes, Carbohydr. Res. 122(2), 241-248.

Tajmir-Riahi, H.A. (1988): Interaction of D-glucose with alkaline earth metal ions. Synthesis, spectroscopic, and structural characterization of $\mathrm{Mg}(\mathrm{II})$ - and $\mathrm{Ca}(\mathrm{II})-\mathrm{D}$ glucose adducts and the effect of metal-ion binding on anomeric configuration of the sugar, Carbohydr. Res. 183(1), 35-46.

Taylor, K.A. and Buchanan-Smith, J.G. (1992): A colorimetric method for the quantification of uronic acids, and a specific assay for galacturonic acid, Anal. Biochem. 201(1), 190-196.

Williams, J.C., Fowler, C.S., Lyon, M.S. and Merrill, T.L. (1977): Metallic catalysts in the oxidative degradation of paper, In: Williams, J.C. (ed.), Preservation of Paper and Textiles of Historic and Artistic Value, Advances in Chemistry Series, No. 164, American Chemical Society, Washington, DC, USA, pp. 37-61.

Withmore, P.M. and Bogaard, J. (1994): Determination of the cellulose scission route in the hydrolytic and oxidative degradation of paper, Restaurator, 47(1), 2645.

Yu, L., Rae, M. and Ni, Y. (2004): Formation of oxalate from the $\mathrm{Mg}(\mathrm{OH})_{2}$-Based peroxide bleaching of mechanical pulps, J. Wood Chem. Technol. 24(4), 341-355. Zou, X., Gurnagul, N., Uesaka, T. and Bouchard, J. (1994): Accelerated aging of papers of pure cellulose: mechanism of cellulose degradation and paper embrittlement, Polym. Deg. Stab. 43(3), 393-402.

Zou, X., Uesaka, T. and Gurnagul, N. (1996): Prediction of paper permanence by accelerated aging. I: Kinetic analysis of the aging process, Cellulose, 3(4), 243-267. 